\title{
Desired Compensation Adaptive Robust Control of an Active Vibration Isolation System
}

\author{
Bo Zhao $(\mathbb{D}$, Weijia Shi $(\mathbb{D}$, Ming Zhang $(\mathbb{D}$, Jiaxin Li $\mathbb{D}$, and Feng Li $(\mathbb{D}$ \\ Center of Ultra-Precision Optoelectronic Instrument Engineering, Harbin Institute of Technology, Harbin 150001, China \\ Correspondence should be addressed to Weijia Shi; shiweijia@hit.edu.cn
}

Received 3 May 2018; Accepted 19 June 2018; Published 19 July 2018

Academic Editor: Zhile Yang

Copyright ( 2018 Bo Zhao et al. This is an open access article distributed under the Creative Commons Attribution License, which permits unrestricted use, distribution, and reproduction in any medium, provided the original work is properly cited.

\begin{abstract}
Active vibration isolation system (AVIS) has attracted increasing attention of researchers in precision engineering. In this paper, a desired compensation adaptive robust controller (DCARC) is proposed for an AVIS developed in our laboratory. The AVIS composed of one platform and three active isolators is required to achieve high-performance vibration isolation as well as low trajectory tracking error for positioning. The vertical three degrees of freedom (DOFs) and horizontal three DOFs are decoupled by the joint bearing of the isolators. The dynamic model of the system is built and is simplified to three single-input-single-output (SISO) systems. The DCARC control scheme is then proposed, which contains a deterministic robust control (DRC) term and an adaptive control (AC) term. The high performance in vibration isolation and positioning can be subsequently achieved, even the actual load and system stiffness are unknown and there exists direct bounded disturbance on the platform. The AC term is designed to estimate the unknown parameters of the system. The DRC term can improve the robustness of the system, which is used to reject the direct disturbance and the parameter estimation error. Furthermore, the computing time and the influence of the measurement noise can be reduced effectively by reason of desired compensation. The numerical simulation and comparative experiments are carried out under the conditions of using DCARC, DRC, and AC controllers. The experimental results validate that the proposed DCARC control strategy outperforms other control method and possesses both high-performance vibration isolation and low tracking error.
\end{abstract}

\section{Introduction}

Vibration isolation system is widely used in industrial equipment $[1,2]$, building structure $[3,4]$, and commercial vehicles [5-7], to protect the isolating object, such as human and structure, from being damaged by vibration with certain frequency regions. Especially in recent years, with the rapid development of nanoprecision technology, ultraprecision positioning devices, nanolevel measuring instruments, which are extensively used in medical research, biotechnology, semiconductor manufacturing, and space exploring, are demanding an increasingly need for high-performance vibration isolation system [8-14]. According to the source, vibration can be divided into two categories, the ground vibration which is caused by geodetic pulsation, wind blowing, automobile moving, people walking, and so forth, transferred via the suspension of the system, and the load vibration which is caused by inertial force from a moving load or other disturbance directly acted on the isolation system [15]. To reduce the ground vibration, an isolation system with low suspension stiffness is more susceptible, the zero stiffness is ideal, and the performance of transmissibility is the priority of the isolation system. However, the load capacity of the system will decrease with the reducing stiffness [16]. To reduce the load vibration, an isolation system with high suspension stiffness is more susceptible, the infinite stiffness is ideal, and the performance of compliance is the priority of the isolation system. However, the isolation system will be more sensitive to the ground vibration with the increasing stiffness. So in the conventional passive vibration isolation system, a trade-off between load capacity and isolation performance is inevitable [17].

Active vibration isolation system (AVIS) has attracted significant research attention in recent years, which can give consideration to both load capacity and isolation performance [18]. The focus of AVIS research lies on three things, mechanical design without cross-coupling in each actuator, lowfrequency vibration sensing, and control of the isolation system [19]. With the increasing demands to AVIS performance of 
broad frequency, high positioning accuracy, low transmissibility, and high compliance, the research interest is brought much to the control method [20]. Holterman and de Vries proposed an active damping method based on decoupled collocated control in combination with a passive multiple-inputmultiple-output (MIMO) control law to avoid the modelling uncertainty [21]. The modal damping can be realized under the mild condition by using piezoelectric Smart Discs made by piezoelectric material [22], and the robust stability can be retained based on a simple kinematic model rather than a complex dynamic model with specific parameters of the system. Heertjes et al. proposed a switching control method with two regimes to enhance both the steady-state noise properties of the passive isolation system and disturbance rejection properties of transients [23]. The transient oscillations can be removed from the velocity response, and the steady-state noise can be avoided at small velocity by sky-hook damping. To resolve the subcritical vibration isolation problem, which is the natural frequency of the uncoupled source body larger than that of the uncoupled receiving body, Alujevic et al. used an inerter element to enhance the stability margins of the feedback disturbance rejection scheme of two degrees of freedom (DOFs) system [24]. The specific kinetic energy index monotonically decreased with the increase in the feedback gain, and the higher the gain, the lower the velocity response. Beijen et al. proposed a self-turning feedforward control method for an air mount systems to compensate the static damping and stiffness [25]. A higher-order weak integrator can limit the gain of the controller to prevent drift and actuator saturation, and an infinite impulse response (IIR) filter with fixed poles and self-turning zeros was implemented to online adjust the parameters by using filtered least mean squares (FLMS) optimization and residual noise shaping.

In this paper, a desired compensation adaptive robust control (DCARC) strategy for an active vibration isolation system in the vertical three degrees of freedom is proposed. The focused indexes of the AVIS are transmissibility, ability to disturbance rejection, and positioning error. The DCARC control scheme is composed of a deterministic robust control (DRC) term and an adaptive control (AC) term. The AC term is designed to estimate the unknown parameters of the system. The DRC term can improve the robustness of the system, which is used to reject the direct disturbance and the parameter estimation error. The performance of DCARC is validated by both numerical simulation and experiment. The DRC and AC controllers are also tested as a comparison. The results show that the proposed DCARC control strategy outperforms other control method and possesses both highperformance vibration isolation and low tracking error.

\section{System Description and Dynamic Modeling}

2.1. System Description. The schematic illustration of the isolator is shown in Figure 1. Each isolator contains two voice coil motor (VCM), which can provide a vertical force $F_{z}$ and a horizontal force $F_{y}$. The inclination of the platform can be decoupled into vertical movement and horizontal movement by the joint bearing. So, the vertical 3 DOFs, which are $Z, \theta_{x}$, and $\theta_{y}$, and the horizontal $3 \mathrm{DOFs}$, which are $X, Y$, and $\theta_{z}$, can be considered as two independents because the tilt angle of the platform is extreme small. The compressed air in the main air chamber from external source is used to support the platform and the load. The air spray out from the orifice can form a thin film which is the air bearing in this paper. There is no interference between the horizontal air bearing and the vertical air bearing, so the vertical movement and the horizontal movement of the AVIS are decoupled by the mechanical structure. The horizontal stiffness $k_{h}$ of the isolator is close to zero without the active control of the horizontal actuator, and the vertical stiffness $k_{f}$ is related to the load. The horizontal damping coefficient $c_{h}$ and the vertical damping coefficient $c_{f}$ are close to zero. The travel range along $z$-axis is $1 \mathrm{~mm}$ and that along $x$-axis and $y$-axis is $2 \mathrm{~mm}$.

The AVIS in this paper is composed of one platform and three isolators, as shown in Figure 2. The centers of the three isolators are at the vertexes of an isosceles triangle, $O$ represents the center of the platform, and $O_{1}, O_{2}$, and $O_{3}$ are the supporting points of the isolators to the platform. The platform is controlled by three horizontal forces $F_{h 1}, F_{h 2}$, and $F_{h 3}$ and three vertical forces $F_{v 1}, F_{v 2}$, and $F_{v 3}$. As shown in Figure 2, the parameters $L_{h}$ and $L_{v}$ represent the arm of force to point $O$, for example, $L_{h 2 z}$ and $L_{v 1 x}$, respectively, represent the arm of horizontal force $F_{h 2}$ to $z$-axis and the vertical forces $F_{v 1}$ to $x$-axis, and each force has two arms. The parameters $L_{1 x}$ and $L_{1 y}$ represent the distances from $O_{1}$ to $X O Z$ plane and $Y O Z$ plane. The air pressure in the main chamber of AVI-2 is larger than the other two because of the configuration of the isolators. The platform will move suddenly at the moment when the high-pressure air source is open, because once the air bearings work, the friction coefficient changes from a large value to nearly zero. So, the mechanical limits are mounted around the horizontal air bearing to restrict the horizontal travel range. The linear travel ranges of the AVIS are $2 \mathrm{~mm}$ along the $x$-axis and $y$-axis and $0.8 \mathrm{~mm}$ along the $z$-axis. The rotational travel ranges are 179 arc second around $x$-axis, 541 arc second around $y$-axis, and 448 arc second around $z$-axis.

2.2. Dynamic Modeling. Due to $k_{h}, c_{h}$, and $c_{f}$ are close to zero, the dynamic equations of the six degrees of the AVIS are given by

$$
\begin{aligned}
& m \ddot{x}=-F_{h 2}, \\
& m \ddot{y}=F_{h 1}+F_{h 3}, \\
& I_{z} \ddot{\theta}_{z}= F_{h 1} L_{h 1 z}+F_{h 2} L_{h 2 z}-F_{h 3} L_{h 3 z}, \\
& m \ddot{z}+3 k_{f}\left(z-z_{0}\right)= F_{v 1}+F_{v 2}+F_{v 3}, \\
& I_{x} \ddot{\theta}_{x}+k_{f}\left(L_{1 x}^{2}+L_{2 x}^{2}+L_{3 x}^{2}\right)\left(\theta_{x}-\theta_{x 0}\right) \\
&=F_{h 1} L_{h 1 x}+F_{h 3} L_{h 3 x}+F_{v 2} L_{v 2 x} \\
&-F_{v 1} L_{v 1 x}-F_{v 3} L_{v 3 x}, \\
& I_{y} \ddot{\theta}_{y}+k_{f}\left(L_{1 y}^{2}+L_{3 y}^{2}\right)\left(\theta_{y}-\theta_{y 0}\right) \\
&= F_{h 2} L_{h 2 y}+F_{v 2} L_{v 2 y}+F_{v 3} L_{v 3 y}-F_{v 1} L_{v 1 y},
\end{aligned}
$$




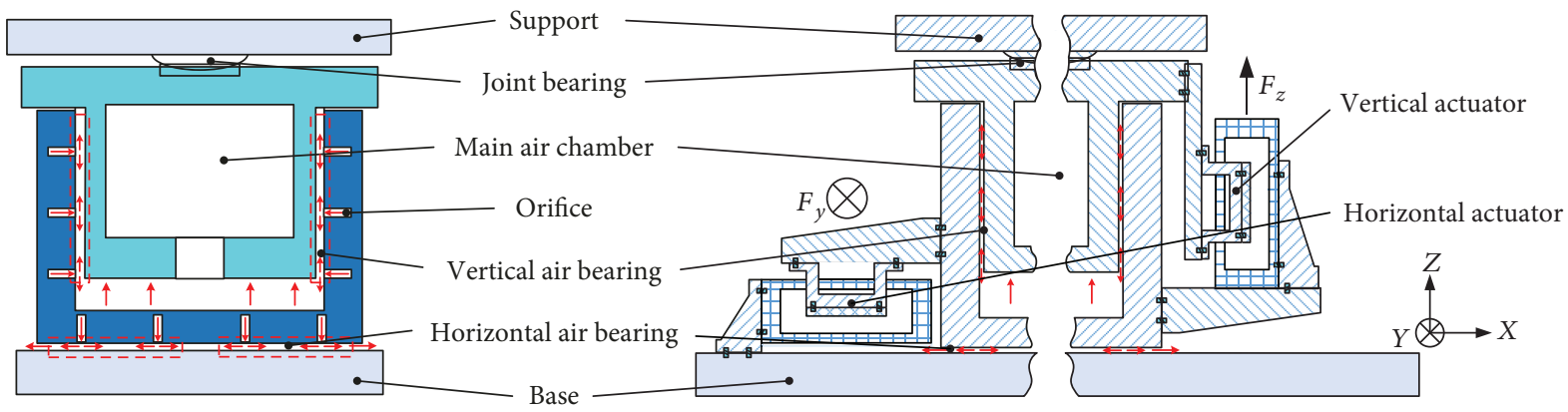

Figure 1: Conceptual design of the isolator.

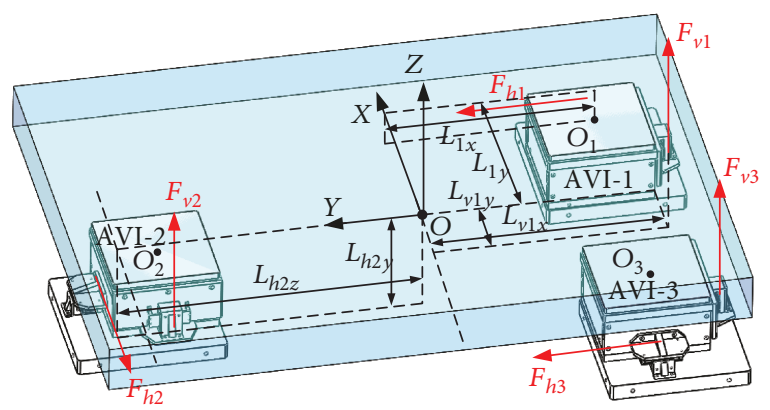

Figure 2: Scheme of active vibration isolation system.

where (1) can be represented in matrix form as

$$
\mathbf{M} \ddot{q}+\mathbf{K} q-\mathbf{K} q_{0}=\boldsymbol{\Phi} \cdot f,
$$

where

$$
\begin{aligned}
q & =\left[x, y, \theta_{z}, z, \theta_{x}, \theta_{y}\right]^{T}, \\
q_{0} & =\left[x_{0}, y_{0}, \theta_{z 0}, z_{0}, \theta_{x 0}, \theta_{y 0}\right]^{T}, \\
f & =\left[F_{h 1}, F_{h 2}, F_{h 3}, F_{v 1}, F_{v 2}, F_{v 3}\right]^{T}, \\
\mathbf{M} & =\operatorname{diag}\left\{m, m, I_{z}, m, I_{x}, I_{y}\right\}, \\
\mathbf{K} & =\operatorname{diag}\left\{0,0,0,3 k_{f}, k_{f}\left(L_{1 x}^{2}+L_{2 x}^{2}+L_{3 x}^{2}\right), k_{f}\left(L_{1 y}^{2}+L_{3 y}^{2}\right)\right\}, \\
\mathbf{\Phi} & =\left[\begin{array}{cccccc}
0 & -1 & 0 & 0 & 0 & 0 \\
1 & 0 & 1 & 0 & 0 & 0 \\
L_{h 1 z} & L_{h 2 z} & -L_{h 3 z} & 0 & 0 & 0 \\
0 & 0 & 0 & 1 & 1 & 1 \\
L_{h 1 x} & 0 & L_{h 3 x} & -L_{v 1 x} & L_{v 2 x} & -L_{v 3 x} \\
0 & L_{h 2 y} & 0 & -L_{v 1 y} & L_{v 2 y} & L_{v 3 y}
\end{array}\right] .
\end{aligned}
$$

The driving forces of VCMs are given by

$$
f=K_{F I} I .
$$

where $K_{F I}$ is the thrust coefficient of the VCM; $I=$ $\left[I_{1}, I_{2}, I_{3}, I_{4}, I_{5}, I_{6}\right]^{T}$ is the control current vector.
Single-input-single-output (SISO) controllers can be designed to generate control currents. Define the imaginary SISO controllers output as $u_{c}=\left[u_{1}, u_{2}, u_{3}, u_{4}, u_{5}, u_{6}\right]^{T}$. The relationship between $u_{c}$ and control currents can be derived as

$$
u_{c}=\boldsymbol{\Phi} \cdot f=K_{F I} \Phi \cdot I .
$$

Substituting (5) into (2), the dynamic equation can be written as

$$
\mathbf{M} \ddot{q}+\mathbf{K} q-\mathbf{K} q_{0}=u_{c} .
$$

Equation (6) shows that the model of AVIS has been decoupled. As we concern the vertical three DOFs, the main object of this paper is to design control input $u_{v}=$ $\left[u_{4}, u_{5}, u_{6}\right]^{T}$ to achieve active control of the vertical three DOFs of the system.

\section{Desired Compensation Adaptive Robust Control (DCARC) Approach}

3.1. Controller Design. Consider the $Z$-direction motion of the platform described as

$$
m \ddot{z}+3 k_{f}\left(z-z_{0}\right)=u_{4} .
$$

Defining the state variables $x_{1}=z$ and $x_{2}=\dot{z}$, the dynamic equation in (7) can be rewritten in the following state-space form

$$
\begin{aligned}
& \dot{x}_{1}=x_{2}, \\
& \dot{x}_{2}=\frac{1}{\theta_{1}}\left(u-\theta_{2} x_{1}+d(x, t)\right),
\end{aligned}
$$

where $u=u_{4}$ is controller output, $\theta_{1}=m$ and $\theta_{2}=3 k_{f}$ are unknown model parameters, and $d(x, t)$ is external disturbance and unmodeled dynamics including ground vibration. Define a vector as $\theta=\left[\theta_{1}, \theta_{2}\right]^{T}$.

It is assumed that

$$
\begin{aligned}
\theta_{i} \in \Omega_{\theta} & \triangleq\left\{\theta_{i}: \theta_{i, \text { min }}<\theta_{i}<\theta_{i, \max }\right\}, \quad i=1,2, \\
|d(x, t)| & \leq \delta,
\end{aligned}
$$

where $\theta_{\min }=\left[\theta_{1 \min }, \theta_{2 \min }\right]^{T}, \theta_{\max }=\left[\theta_{1 \max }, \theta_{2 \max }\right]^{T}$, and $\delta$ are known. 
Define an error operator as

$$
s=\dot{e}+k_{1} e,
$$

where $e=x_{1}-x_{1 d}, x_{1 d}$ is the reference trajectory, and $k_{1}$ is a positive gain. Differentiating (10) and noting (8), derivative of error can be written as

$$
\begin{aligned}
\theta_{1} \dot{s} & =\theta_{1}\left(\ddot{x}_{1}-\ddot{x}_{1 d}+k_{1} \dot{e}\right)=u-\theta_{2} x_{1}+d(x, t)-\theta_{1} \ddot{x}_{1 d}+\theta_{1} k_{1} \dot{e} \\
& =u+\varphi^{T} \theta+d(x, t),
\end{aligned}
$$

where $\varphi=\left[k_{1} \dot{e}-\ddot{x}_{1 d},-x_{1}\right]^{T}$, and $\varphi_{d}$ and $\tilde{\varphi}$ are defined as $\varphi_{d}=\left[k_{1} \dot{e}-\ddot{x}_{1 d},-x_{1 d}\right]^{T}$ and $\tilde{\varphi}=\varphi-\varphi_{d}$. There exists a certain function $\delta_{\varphi}$ satisfying

$$
\left|\tilde{\varphi}^{T} \theta\right|=\left|\varphi^{T} \theta-\varphi_{d}^{T} \theta\right| \leq \delta_{\varphi}|s| .
$$

The DCARC control law is designed as

$$
\begin{aligned}
u & =u_{a}+u_{r}, \\
u_{a} & =-\varphi_{d}^{T} \widehat{\theta}, \\
u_{r} & =u_{r 1}+u_{r 2}, \quad u_{r 1}=-k_{s} s,
\end{aligned}
$$

where $u_{a}$ is the model compensation term, and $\widehat{\theta}$ is the estimate of $\theta$. The parameter adaptation law is given by

$$
\begin{gathered}
\dot{\hat{\theta}}=\operatorname{Pr} \operatorname{oj}_{\widehat{\theta}}\left(\Gamma \varphi_{d} s\right), \\
\operatorname{Proj}_{\widehat{\theta}_{i}}\left(\bullet_{i}\right)= \begin{cases}0, & \text { if } \widehat{\theta}_{i}=\theta_{i \max }, \bullet_{i}>0, \\
0, & \text { if } \widehat{\theta}_{i}=\theta_{i \min }, \bullet_{i}<0, \\
\bullet_{i}, & \text { otherwise, }\end{cases}
\end{gathered}
$$

where $\Gamma$ is a diagonal symmetric positive definite matrix. The projection mapping is a simple output limitation treatment for $\widehat{\theta}$ and it guarantees

$$
\begin{aligned}
& \text { (i) } \widehat{\theta} \in \Omega_{\theta} \triangleq\left\{\widehat{\theta}: \theta_{\min } \leq \widehat{\theta} \leq \theta_{\max }\right\}, \\
& \text { (ii) } \tilde{\theta}^{T}\left(\Gamma^{-1} \operatorname{Pr}_{\hat{\theta}}\left(\Gamma \varphi_{d} s\right)-\varphi_{d} s\right) \leq 0,
\end{aligned}
$$

where $\tilde{\theta}=\widehat{\theta}-\theta$ is the estimation error. Due to the reason that using the desired trajectory instead of the measurement output to calculate $\varphi$, the computing time and the influence of the measurement noise can be reduced effectively.

$u_{r}$ is the deterministic robust control term. $u_{r 1}$ is a linear feedback control to stabilize the nominal system, and the feedback gain $k_{s}$ satisfies

$$
k_{s} \geq k_{s 1}+\delta_{\varphi}
$$

where $k_{s}$ and $k_{s 1}$ are positive; $u_{r 2}$ is a robust feedback term which can reduce the influence of parameter uncertainty and disturbance and should satisfy

$$
\begin{aligned}
& \text { (i) } s u_{r 2} \leq 0, \\
& \text { (ii) } s\left(u_{r 2}-\varphi_{d}^{T} \tilde{\theta}+d(x, t)\right) \leq \varepsilon,
\end{aligned}
$$

where $\varepsilon$ is a small real positive constant which can be designed; $u_{r 2}$ can be chosen as

$$
u_{r 2}=-h \tanh \left(\frac{\kappa h}{\varepsilon} s\right)
$$

where $\kappa=0.2785, h \geq\left\|\theta_{M}\right\|\left\|\varphi_{d}\right\|+\delta$, and $\theta_{M}=\theta_{\max }-\theta_{\min }$.

The DCARC control block diagram is shown in Figure 3. The DRC can reduce the influence of disturbance, but it is difficult to realize zero tracking error. The AC can eliminate the influence of parametric uncertainties by using adaptive law to estimate model parameters and realize asymptotic tracing. Adaptive robust control (ARC) which combines DRC and AC features accurate trajectory tracking with parametric uncertainty and high robustness. Furthermore, due to the reason that using the desired trajectory instead of measurement output to calculate regressor, the computing time and the influence of the measurement noise can be reduced effectively.

\subsection{Stability Analysis}

Theorem 1. For the system in (8), with the DCARC control law (13) and the parameter adaptation law (14), the following results hold

(A) In general, all signals in system (8) are bounded. Furthermore, the positive definite function $V_{s}$ is defined as

$$
V_{s}=\frac{1}{2} \theta_{1} s^{2},
$$

which is bounded above by

$$
V_{s} \leq V_{s}(0) \exp (-\lambda t)+\frac{\varepsilon}{\lambda}[1-\exp (-\lambda t)],
$$

where $\lambda=2 k_{s 1} / \theta_{1 \max }$.

(B) If, after a finite time, the system is subjected to parametric uncertainties only (i.e., all the disturbances vanish after a finite time), in addition to results in (A), the tracking error will converge to zero asymptotically, that is, $e \rightarrow 0$ and $s \rightarrow 0$ as $t \rightarrow \infty$.

Proof. Differentiating $V_{s}$ results in

$$
\begin{aligned}
\dot{V}_{s} & =\theta_{1} \dot{s} \dot{s}=s\left(-k_{s} s+u_{r 2}-\varphi_{d}^{T} \widehat{\theta}+\varphi^{T} \theta+d(x, t)\right) \\
& =-k_{s} s^{2}+s\left(\varphi^{T} \theta-\varphi_{d}^{T} \theta\right)+s\left(u_{r 2}-\varphi_{d}^{T} \tilde{\theta}+d(x, t)\right) \\
& \leq-k_{s} s^{2}+\delta_{\varphi} s^{2}+s\left(u_{r 2}-\varphi_{d}^{T} \tilde{\theta}+d(x, t)\right) \\
& \leq-k_{s 1} s^{2}+s\left(u_{r 2}-\varphi_{d}^{T} \tilde{\theta}+d(x, t)\right) .
\end{aligned}
$$




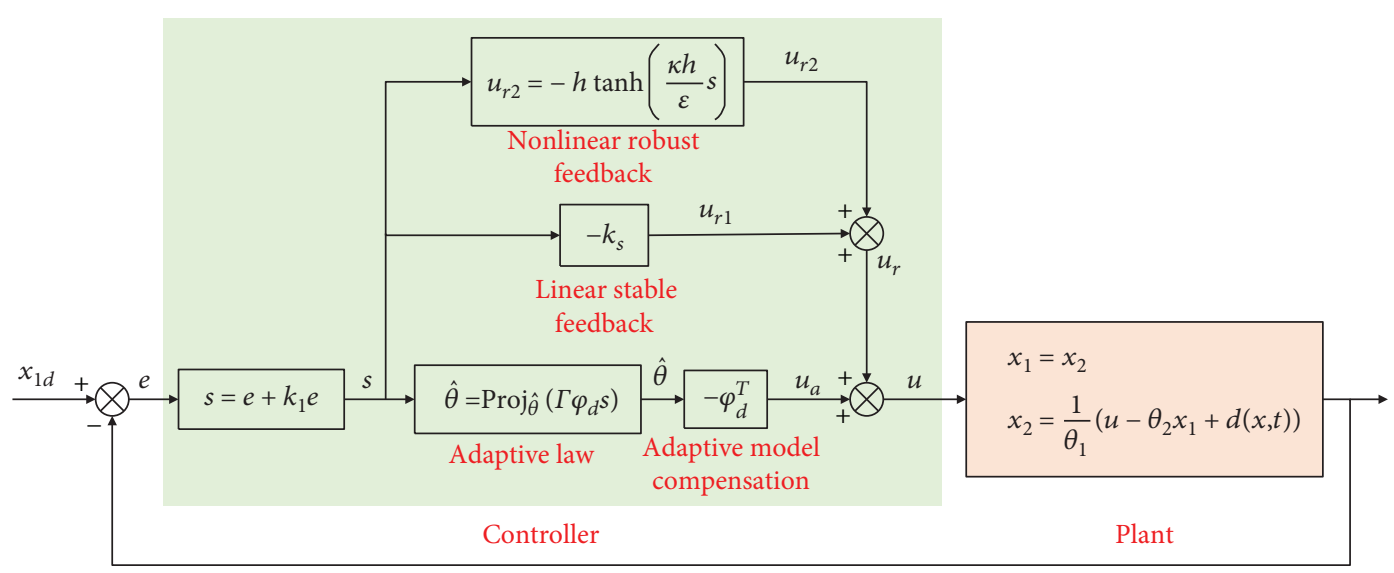

FiguRe 3: DCARC block diagram.

Noting condition ii of (17) and selecting $\lambda=2 k_{s 1} / \theta_{1 \text { max }}$, we have

$$
\dot{V}_{s} \leq-k_{s 1} s^{2}+\varepsilon=-\frac{2 k_{s 1}}{\theta_{1}} V_{s}+\varepsilon \leq-\frac{2 k_{s 1}}{\theta_{1 \max }} V_{s}+\varepsilon=-\lambda V_{s}+\varepsilon,
$$

which can further result in (20) and thus proves the results in (A) of Theorem 1 .

If the disturbances vanish after a finite time, that is, $d(x, t)=0, \quad \forall t \geq t_{0}$, choose a positive definite function $V_{a}$ as

$$
V_{a}=V_{s}+\frac{1}{2} \tilde{\theta}^{T} \Gamma^{-1} \tilde{\theta}
$$

Noting condition i of (17) and condition ii of (15), we can obtain

$$
\begin{aligned}
\dot{V}_{a}= & \dot{V}_{s}+\tilde{\theta}^{T} \Gamma^{-1} \dot{\tilde{\theta}}=-k_{s} s^{2}+s\left(\varphi^{T} \theta-\varphi_{d}^{T} \theta\right)+s\left(u_{r 2}-\varphi_{d}^{T} \tilde{\theta}\right) \\
& +\tilde{\theta}^{T} \Gamma^{-1} \dot{\hat{\theta}} \leq-k_{s} s^{2}+\delta_{\varphi} s^{2}+s\left(u_{r 2}-\varphi_{d}^{T} \tilde{\theta}\right)+\tilde{\theta}^{T} \Gamma^{-1} \dot{\hat{\theta}} \\
\leq & -k_{s 1} s^{2}+s u_{r 2}+\tilde{\theta}^{T} \Gamma^{-1} \dot{\widehat{\theta}}-\tilde{\theta}^{T} \varphi_{d} s \leq-k_{s 1} s^{2} \\
& +\tilde{\theta}^{T}\left(\Gamma^{-1} \dot{\widehat{\theta}}-\varphi_{d} s\right)=-k_{s 1} s^{2}+\tilde{\theta}^{T}\left(\Gamma^{-1} \operatorname{Pr} \operatorname{oj}_{\hat{\theta}}\left(\Gamma \varphi_{d} s\right)-\varphi_{d} s\right) \\
\leq & -k_{s 1} s^{2} \leq 0 .
\end{aligned}
$$

Therefore, $V_{a}(t) \leq V_{a}(0)$, that is, $V_{a}$ has an upper bound. Integrating both sides of (24), we can obtain

$$
\begin{aligned}
\int_{0}^{t} s^{2}(\tau) d \tau & =-\frac{1}{k_{s 1}} \int_{0}^{t} \dot{V}_{a}(\tau) d \tau=-\frac{1}{k_{s 1}}\left[V_{a}(t)-V_{a}(0)\right] \\
& \leq \frac{1}{k_{s 1}} V_{a}(0)
\end{aligned}
$$

Therefore, $s \in L_{2}$, that is, $s$ is square integrable. Noting $\dot{s}$ is bounded; $s$ is uniformly continuous. By Barbalat's lemma, $s$ converges to zero as $t \rightarrow \infty$, and thus, $e \rightarrow 0$.
TABle 1: Parameters of the AVIS.

\begin{tabular}{lc}
\hline Parameter & Value \\
\hline$m$ & $1300-1500 \mathrm{~kg}$ \\
$I_{x}$ & $6.2-7.2 \mathrm{~kg} \mathrm{~m}^{2}$ \\
$I_{y}$ & $1.6-1.8 \mathrm{~kg} \mathrm{~m}$ \\
$I_{z}$ & $7.7-8.9 \mathrm{~kg} \mathrm{~m}{ }^{2}$ \\
$k_{f}$ & $32-38 \mathrm{kN} / \mathrm{m}$ \\
$L_{1 x}=L_{3 x}$ & $0.935 \mathrm{~m}$ \\
$L_{2 x}$ & $0.905 \mathrm{~m}$ \\
$L_{1 y}=L_{3 y}$ & $0.305 \mathrm{~m}$ \\
$L_{h 1 x}=L_{h 3 x}=L_{h 2 y}$ & $0.291 \mathrm{~m}$ \\
$L_{h 1 z}=L_{h 3 z}$ & $0.519 \mathrm{~m}$ \\
$L_{h 2 z}$ & $1.119 \mathrm{~m}$ \\
$L_{v 1 x}=L_{v 3 x}$ & $1.148 \mathrm{~m}$ \\
$L_{v 1 y}=L_{v 3 y}$ & $0.305 \mathrm{~m}$ \\
$L_{v 2 x}$ & $0.905 \mathrm{~m}$ \\
$L_{v 2 y}$ & $0.213 \mathrm{~m}$ \\
\hline
\end{tabular}

\section{Numerical Simulation}

The proposed control strategy is validated by numerical simulation. The common performance indexes of AVIS which are transmissibility, position tracking error, and compliance are applied to evaluate the quality of the control strategy. Besides the DCARC controller, the DRC controller, the $\mathrm{AC}$ controller, and the passive system are all simulated for a comparison.

The parameters of the AVIS used in the simulation are listed in Table 1.

The transmissibility of system (8) with the DCARC controller, DRC controller, and AC controller is simulated as shown in Figure 4. The natural frequency of the system is $1.4 \mathrm{~Hz}$. With the AC controller, the transmissibility is larger than $0 \mathrm{~dB}$ when the frequency is lower than $0.7 \mathrm{~Hz}$, which 


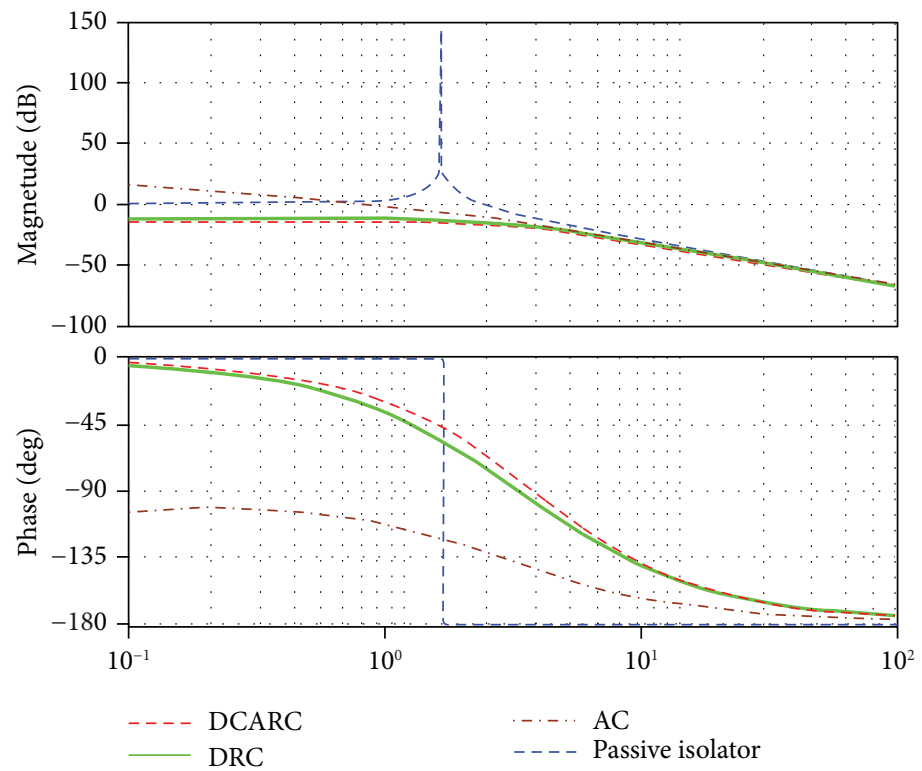

FIgURE 4: Transmissibility.

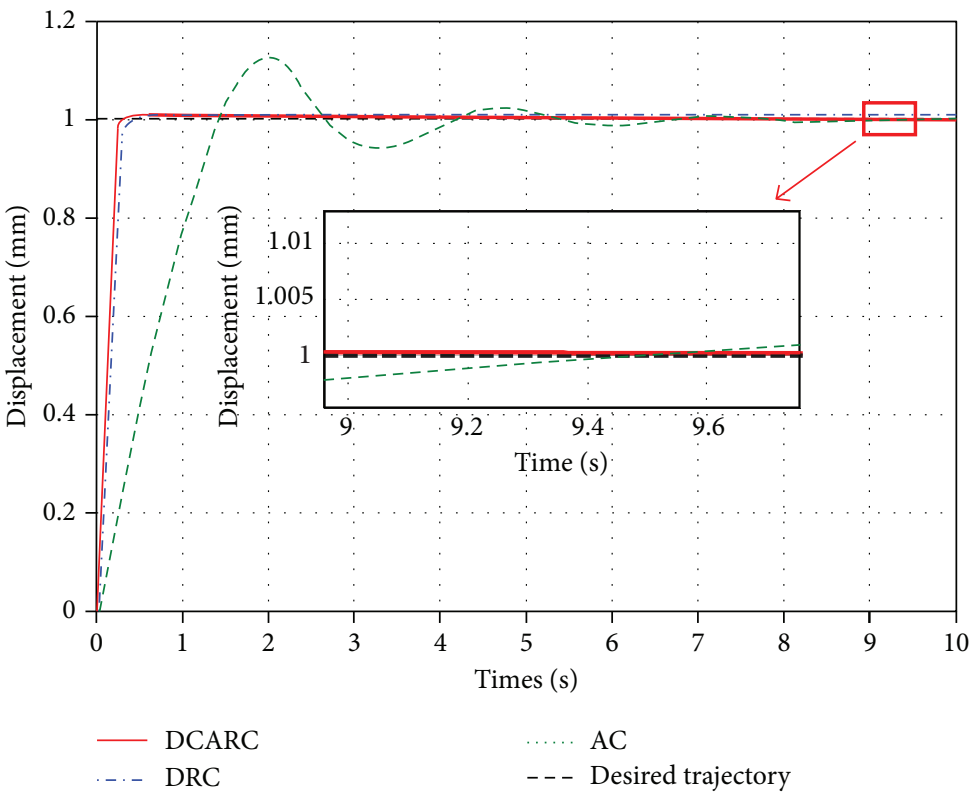

FIgURE 5: Trajectory tracking.

means the vibration from the ground with the frequency lower than $0.7 \mathrm{~Hz}$ will be amplified. With the DCARC controller or DRC controller, the transmissibility is less than $-12 \mathrm{~dB}$ for the entire frequency range. So both the DCARC and DRC controllers can restrain ground vibration effectively.

Figure 5 shows the ability of trajectory tracking with the DCARC controller, DRC controller, or AC controller. The desired trajectory is $1 \mathrm{~mm}$, and there is no external disturbance on the platform. With the DRC controller, the tracking error is not zero due to parametric uncertainties. With the $\mathrm{AC}$ controller, the tracking error can be close to zero but transient time is long. DCARC can realize zero tracking error and short transient time in theory.
The external disturbing force shown in Figure 6(a) is applied to the system (8) with the DCARC controller, DRC controller, or AC controller. The displacement response is shown in Figure 6(b). The maximum displacement is $8 \mu \mathrm{m}$ with the DCARC controller or DRC controller while it is $50 \mu \mathrm{m}$ with the AC controller. The external disturbance can be restrained effectively with the DCARC controller or DRC controller.

\section{Experiment}

5.1. Experiment Setup. The DCARC control strategy is tested on an AVIS in the laboratory as shown in Figure 7. The 


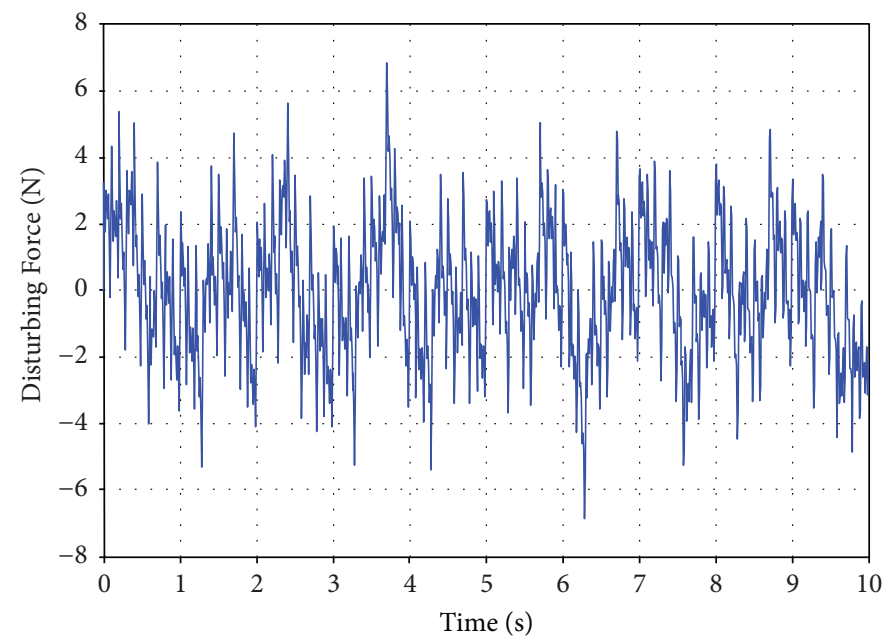

(a)

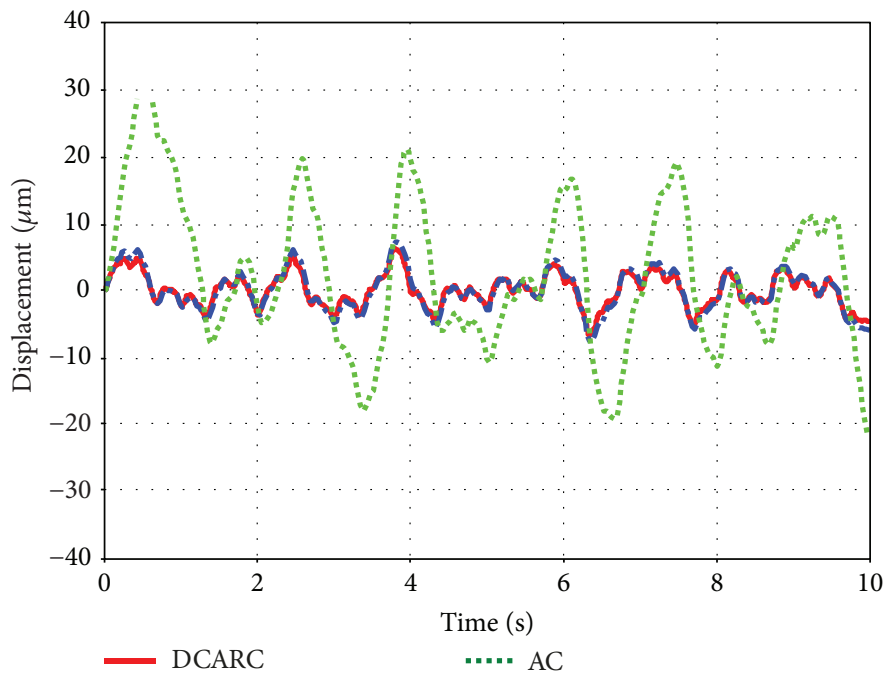

(b)

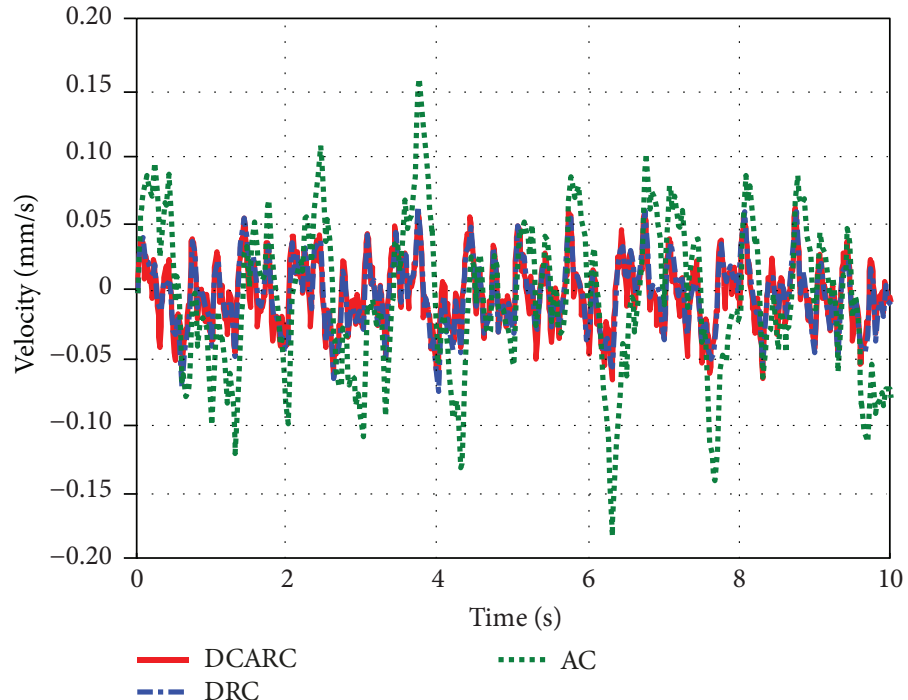

(c)

FIgURE 6: Rejection to disturbing force: (a) disturbing force and (b) displacement response. 


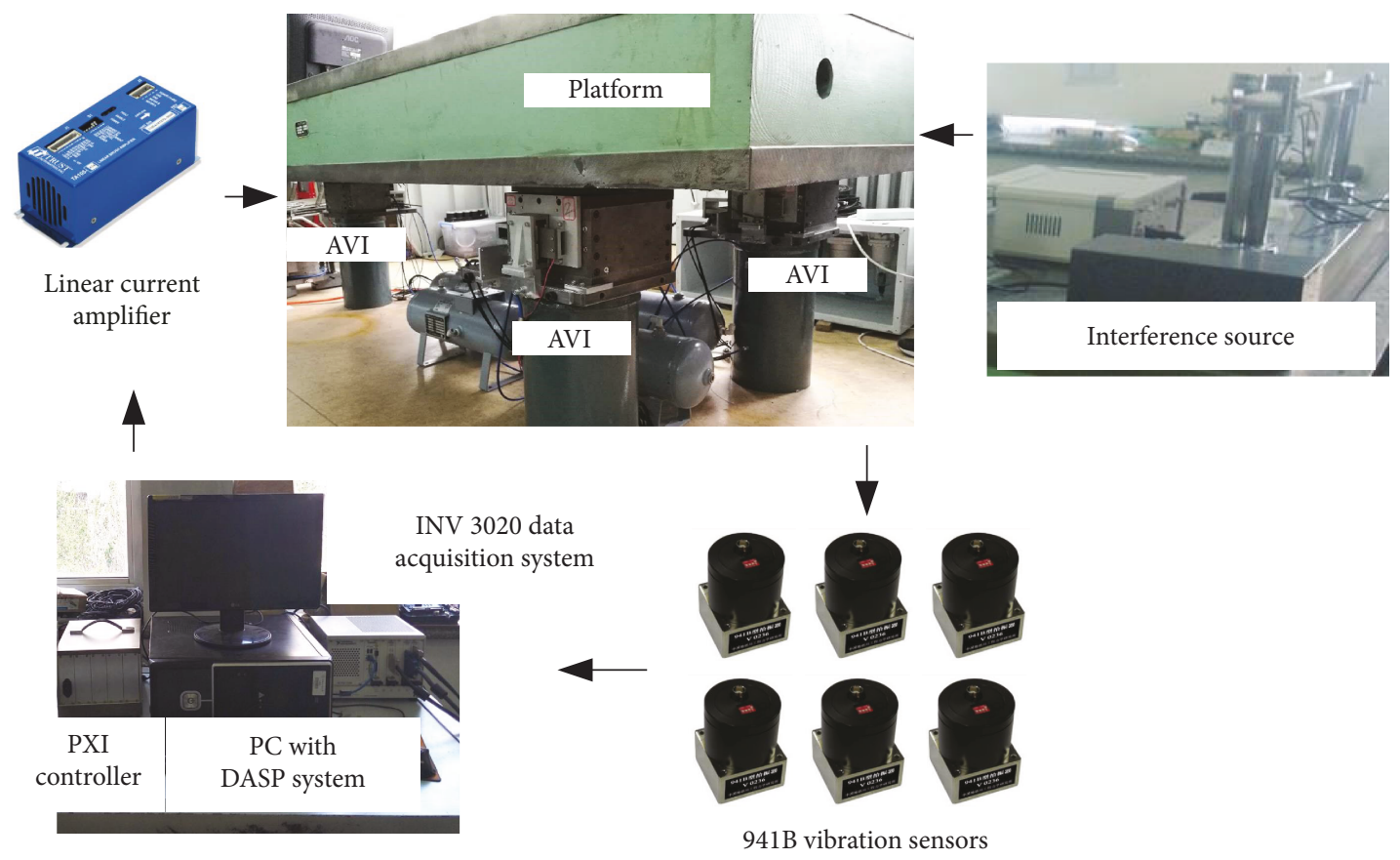

Figure 7: Experiment setup.

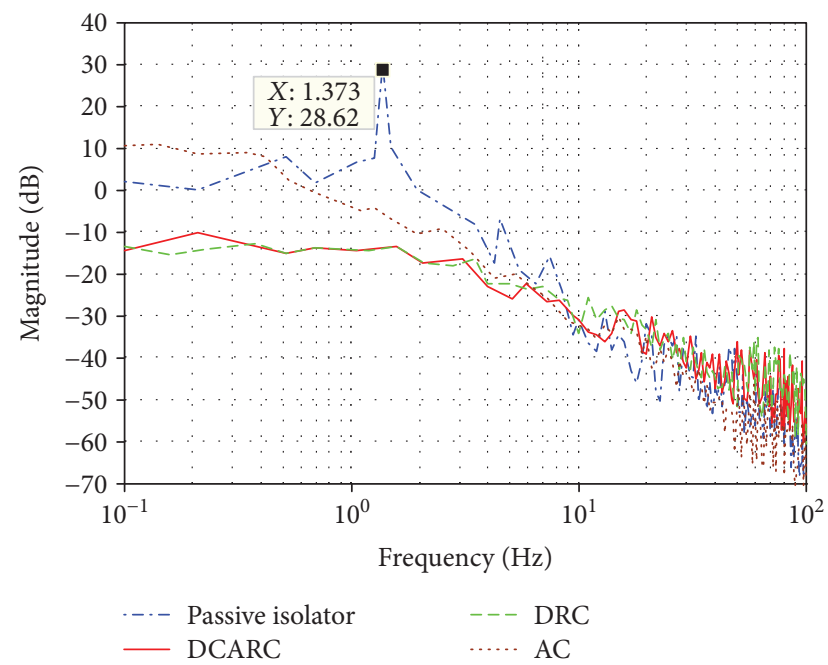

FIGURE 8: Measured transmissibility.

platform is supported by three active vibration isolators. Each isolator has two VCMs, and each VCM needs one current amplifier which is TA115 in this paper. The gas tanks connected to the isolators are used to increase the volume of the main chamber for stabilizing the pressure. The 941B vibration sensors are used to measure the velocity of the platform and the velocity of ground. The velocity data is collected by INV 3020 data acquisition system and is transmitted to PXI controller for feedback control and also to PC for result display by data acquisition and signal processing (DASP) software. The vertical position of the platform is measured by three eddy current sensors which are fixed on the isolators. The resolution of the eddy current sensor is $1 \mu \mathrm{m}$, and the

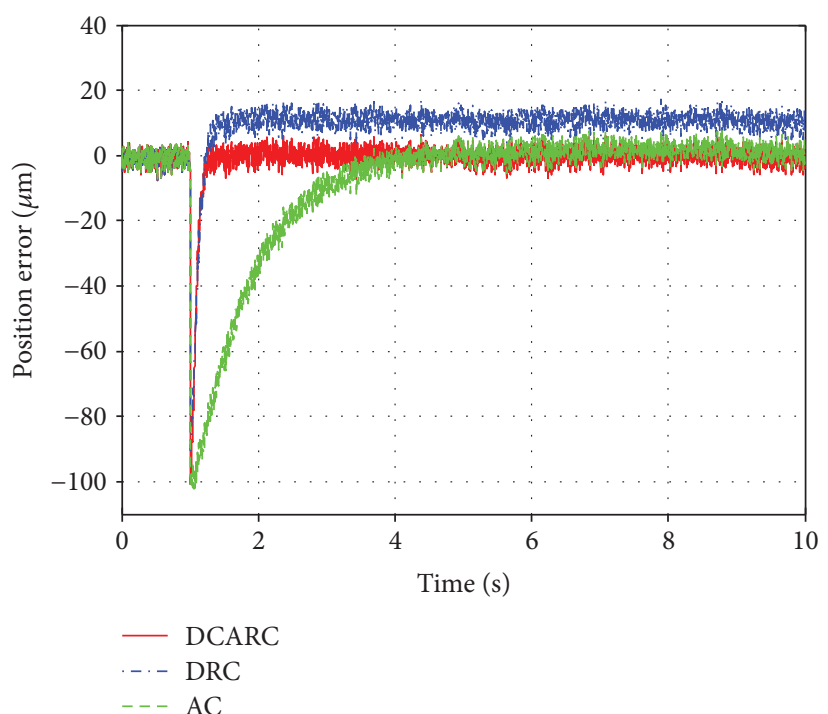

Figure 9: Measured position error of a $0.1 \mathrm{~mm}$ step reference input.

measuring range is $2 \mathrm{~mm}$ to $5 \mathrm{~mm}$; the linearity is $0.12 \% \mathrm{FS}$. The analog voltage signal from the sensor can be collected and processed by the PXI controller. The vibration on the ground comes from the environment. The disturbance acted on the platform is generated by the interference source. The output force of the interference source is programmable.

5.2. Experiment Result. Measured transmissibility is shown in Figure 8 . The blue curve shows that the natural frequency of the passive vibration isolation system is about $1.4 \mathrm{~Hz}$, which is close to the simulation result and the magnitude crosses the $0 \mathrm{~dB}$ line at $2 \mathrm{~Hz}$. With the $\mathrm{AC}$ controller, the vibrations 


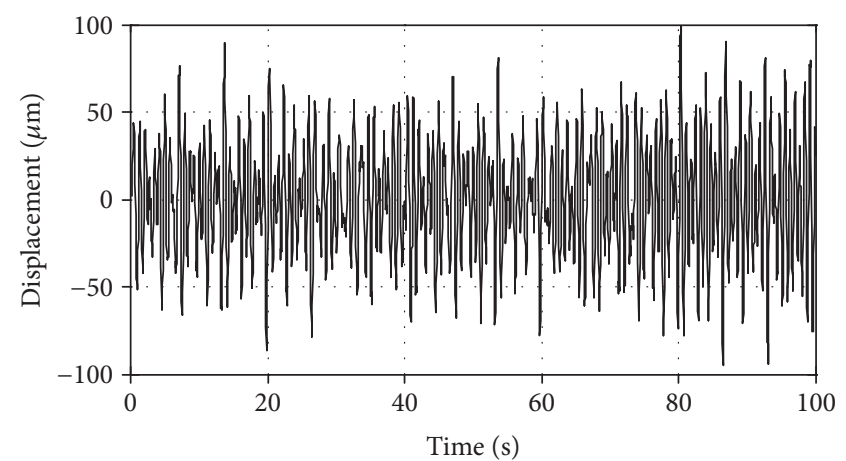

(a)

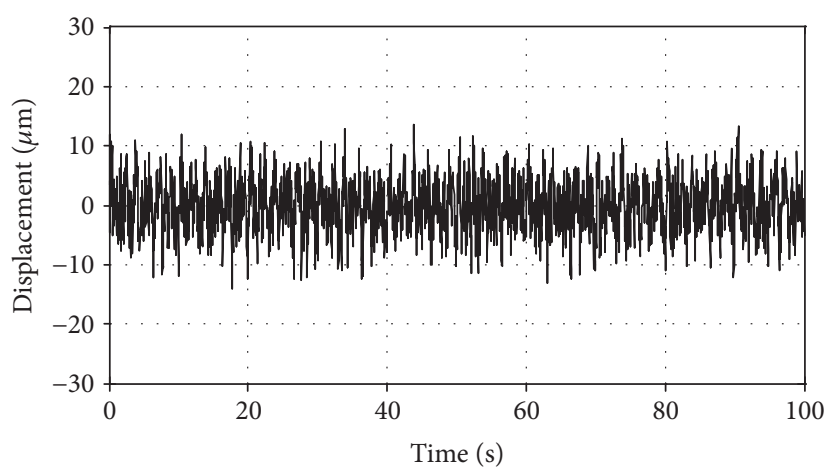

(c)

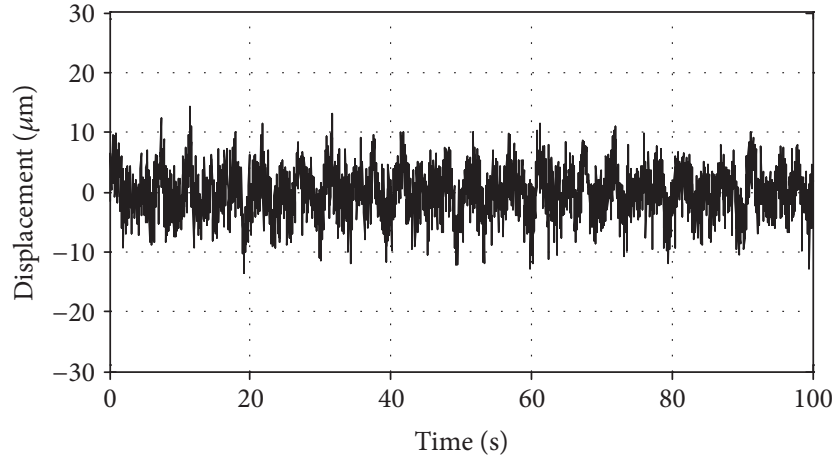

(b)

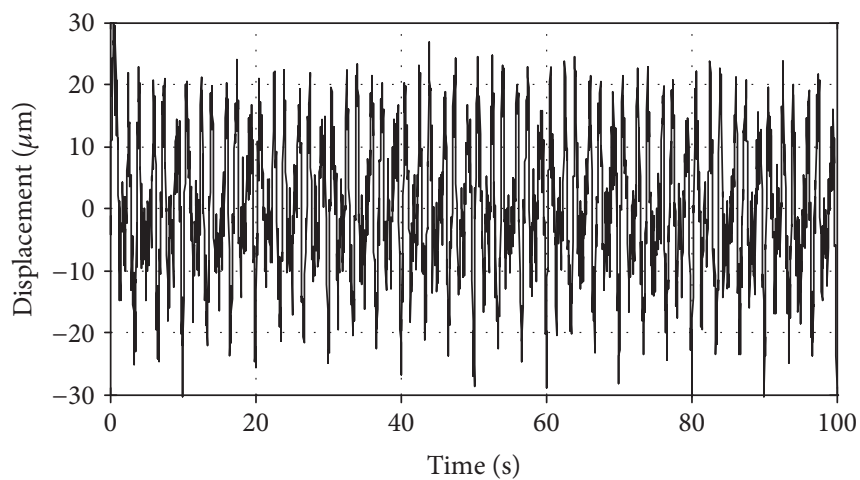

(d)

FIGURE 10: Displacement response to external disturbing force: (a) passive vibration isolation system, (b) AVIS with DCARC controller, (c) AVIS with DRC controller, and (d) AVIS with AC controller.

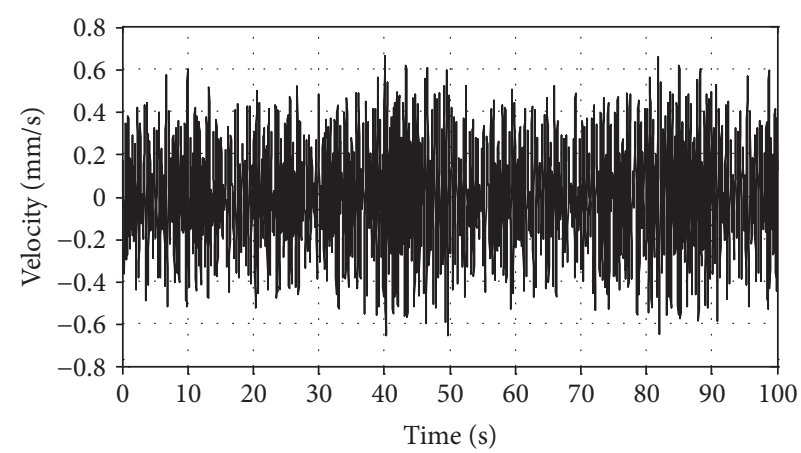

(a)

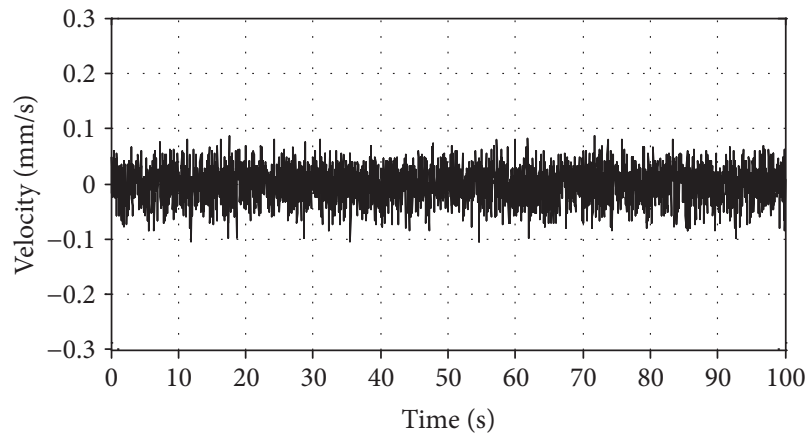

(c)

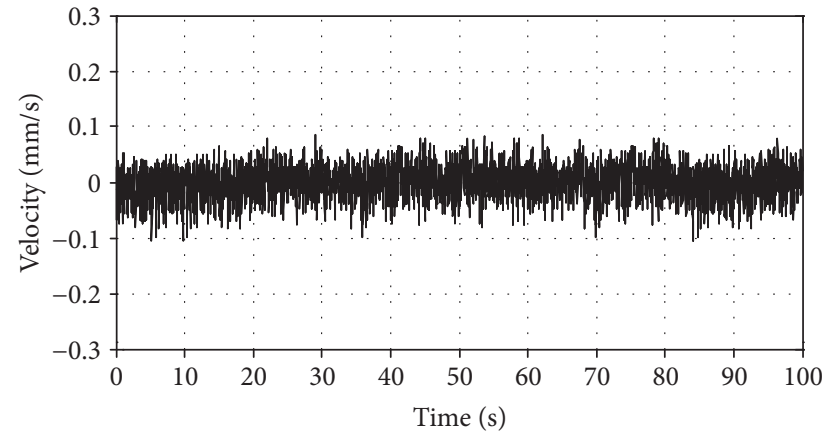

(b)

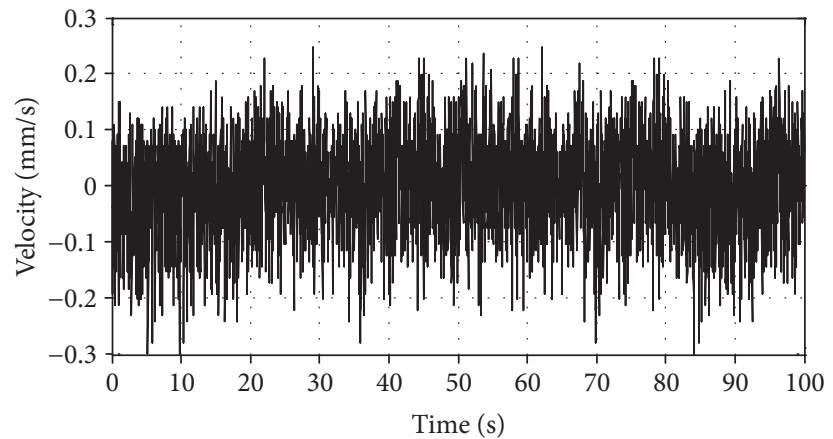

(d)

FIGURE 11: Velocity response to external disturbing force: (a) passive vibration isolation system, (b) AVIS with DCARC controller, (c) AVIS with DRC controller, and (d) AVIS with AC controller. 
below $0.6 \mathrm{~Hz}$ are amplified due to the transmissibility larger than $0 \mathrm{~dB}$. With the DCARC controller or DRC controller, the transmissibility is less than $-10 \mathrm{~dB}$ for the entire frequency range and the system achieves good vibration isolation performance. By using the proposed DCARC controller, the transmissibility is reduced obviously below $9 \mathrm{~Hz}$.

To test the tracking performance, an experiment is carried out. The reference input is $0.1 \mathrm{~mm}$ step signal, and the position error is shown in Figure 9. With the DRC controller, the tracking error is about $10 \mu \mathrm{m}$. With the AC controller, the tracking error is close to zero but transient time is as long as $3 \mathrm{~s}$. With the DCARC controller, the tracking error is nearly zero and the transient time is less than $1 \mathrm{~s}$.

With the external disturbing force, the displacement response and the velocity response of AVIS are tested and shown in Figures 10 and 11. With the AC controller, the maximum displacement and velocity of the platform are about $60 \mu \mathrm{m}$ and about $0.5 \mathrm{~mm} / \mathrm{s}$, respectively. In the case of the DCARC controller and DRC controller, the maximum displacement and velocity are $20 \mu \mathrm{m}$ and less than $0.2 \mathrm{~mm} / \mathrm{s}$, respectively. Compared with passive vibration isolation system, the maximum displacement is reduced from $200 \mu \mathrm{m}$ to $20 \mu \mathrm{m}$ by using the proposed DCARC controller and the maximum velocity is reduced from $1.2 \mathrm{~mm} / \mathrm{s}$ to less than $0.2 \mathrm{~mm} / \mathrm{s}$.

\section{Conclusion}

In this paper, a DCARC control strategy is proposed for an AVIS to achieve high-performance vibration isolation as well as low trajectory tracking error for positioning. The following conclusions can be drawn.

(1) The system composition of the AVIS is introduced. The dynamic model of the AVIS is deduced in the vertical three DOFs and is simplified into three SISO systems.

(2) The DCARC control scheme is proposed where the AC term is designed to estimate the unknown parameters and the DRC term is designed to improve the robustness of the system. Different from the traditional ARC control strategy, desired compensation is employed to reduce the computing time and the influence of the measurement noise.

(3) The numerical simulation and comparative experiments are carried out under the conditions of using the DCARC, DRC, and AC controllers. The experimental results validate that the proposed DCARC control strategy outperforms other control method and possesses both high-performance vibration isolation and low tracking error.

\section{Data Availability}

The simulation data and experiment data used to support the findings are available from the corresponding author upon request.

\section{Conflicts of Interest}

The authors declare that there are no conflicts of interest regarding the publication of this paper.

\section{Acknowledgments}

This work was supported by the National Natural Science Foundation of China Grant no. 51575141, the Natural Science Foundation of Heilongjiang Province Grant no. QC2016065, and the Heilongjiang Postdoctoral Fund Grant no. LBH-Z12115.

\section{References}

[1] C. Sun and V. Jahangiri, "Bi-directional vibration control of offshore wind turbines using a 3D pendulum tuned mass damper," Mechanical Systems and Signal Processing, vol. 105, pp. 338-360, 2018.

[2] X. Sun, J. Xu, X. Jing, and L. Cheng, "Beneficial performance of a quasi-zero-stiffness vibration isolator with time-delayed active control," International Journal of Mechanical Sciences, vol. 82, pp. 32-40, 2014.

[3] J. Wang, C. Zhang, H. Zhu, X. Huang, and L. Zhang, "RBF nonsmooth control method for vibration of building structure with actuator failure," Complexity, vol. 2017, Article ID 2513815, 7 pages, 2017.

[4] H. Anajafi and R. A. Medina, "Comparison of the seismic performance of a partial mass isolation technique with conventional TMD and base-isolation systems under broadband and narrow-band excitations," Engineering Structures, vol. 158, pp. 110-123, 2018.

[5] W. Sun, H. Gao, and O. Kaynak, "Vibration isolation for active suspensions with performance constraints and actuator saturation," IEEE/ASME Transactions on Mechatronics, vol. 20, no. 2, pp. 675-683, 2015.

[6] X. Wang, F. Bi, and H. Du, "Reduction of low frequency vibration of truck driver and seating system through system parameter identification, sensitivity analysis and active control," Mechanical Systems and Signal Processing, vol. 105, pp. 1635, 2018.

[7] X. Chen and Y. Zhou, "Modelling and analysis of automobile vibration system based on fuzzy theory under different road excitation information," Complexity, vol. 2018, Article ID 2381568, 9 pages, 2018.

[8] M. H. Kim, H. Y. Kim, H. C. Kim, D. Ahn, and D. G. Gweon, "Design and control of a 6-DOF active vibration isolation system using a Halbach magnet array," IEEE/ASME Transactions on Mechatronics, vol. 21, no. 4, pp. 2185-2196, 2016.

[9] M. K. Zhou, X. Xiong, L. L. Chen, J. F. Cui, X. C. Duan, and Z. K. Hu, "Note: a three-dimension active vibration isolator for precision atom gravimeters," Review of Scientific Instruments, vol. 86, no. 4, article 046108, 2015.

[10] B. Tang, L. Zhou, Z. Xiong, J. Wang, and M. Zhan, “A programmable broadband low frequency active vibration isolation system for atom interferometry," Review of Scientific Instruments, vol. 85, no. 9, article 093109, 2014.

[11] M. Takahashi, H. Yoshioka, and H. Shinno, "A newly developed long-stroke vertical nano-motion platform with gravity compensator," Journal of Advanced Mechanical Design, Systems, and Manufacturing, vol. 2, no. 3, pp. 356-365, 2008. 
[12] Y. Yun, L. Wang, B. Zhang, Y. Tian, and T. Zhang, "Design, experiments and multidisciplinary optimization of 2 degreesof-freedom electromagnetic actuator for application in space vibration isolation," Advances in Mechanical Engineering, vol. 9, no. 12, 2017.

[13] Y. K. Zhang, W. B. Dong, W. Liu et al., "Verification of the microgravity active vibration isolation system based on parabolic flight," Microgravity Science and Technology, vol. 29, no. 6, pp. 415-426, 2017.

[14] D. Y. Luo, B. Cheng, B. Wu, X. L. Wang, and Q. Lin, “Design of an active low frequency vibration isolation system for atom interferometry by using sliding mode control," Stavební obzor - Civil Engineering Journal, vol. 26, no. 4, pp. 459-470, 2017.

[15] M. A. Beijen, M. F. Heertjes, H. Butler, and M. Steinbuch, "Practical tuning guide to mixed feedback and feedforward control of soft-mounted vibration isolators," IFAC-PapersOnLine, vol. 49, no. 21, pp. 163-169, 2016.

[16] T. D. Le, M. T. N. Bui, and K. K. Ahn, "Improvement of vibration isolation performance of isolation system using negative stiffness structure," IEEE/ASME Transactions on Mechatronics, vol. 21, no. 3, pp. 1561-1571, 2016.

[17] T. Zhu, B. Cazzolato, W. S. P. Robertson, and A. Zander, "Vibration isolation using six degree-of-freedom quasi-zero stiffness magnetic levitation," Journal of Sound and Vibration, vol. 358, pp. 48-73, 2015.

[18] T. Mizuno, M. Takasaki, D. Kishita, and K. Hirakawa, "Vibration isolation system combining zero-power magnetic suspension with springs," Control Engineering Practice, vol. 15, no. 2, pp. 187-196, 2007.

[19] J. Hong and K. Park, "Design and control of six degree-offreedom active vibration isolation table," Review of Scientific Instruments, vol. 81, no. 3, article 035106, 2010.

[20] G. Ausanio, V. Iannotti, E. Ricciardi, L. Lanotte, C. Hison, and E. Hristoforou, "Potentiality of a novel elastomagnetic attenuator for vibration control," Sensors and Actuators A: Physical, vol. 159, no. 2, pp. 219-226, 2010.

[21] J. Holterman and T. J. A. de Vries, "Active damping based on decoupled collocated control," IEEE/ASME Transactions on Mechatronics, vol. 10, no. 2, pp. 135-145, 2005.

[22] J. Holterman and T. J. A. de Vries, "Active damping within an advanced microlithography system using piezoelectric Smart Discs," Mechatronics, vol. 14, no. 1, pp. 15-34, 2004.

[23] M. F. Heertjes, I. H. Sahin, N. van de Wouw, and W. P. M. H. Heemels, "Switching control in vibration isolation systems," IEEE Transactions on Control Systems Technology, vol. 21, no. 3, pp. 626-635, 2013.

[24] N. Alujevic, D. Cakmak, H. Wolf, and M. Jokic, "Passive and active vibration isolation systems using inerter," Journal of Sound and Vibration, vol. 418, pp. 163-183, 2018.

[25] M. Beijen, M. Heertjes, and H. Butler, "Self-tuning disturbance feedforward control with drift prevention for air mount systems," in 2015 IEEE Conference on Control Applications (CCA), pp. 400-405, Sydney, NSW, Australia, September 2015. 


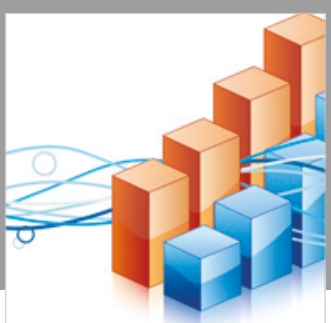

Advances in

Operations Research

\section{-n-m}
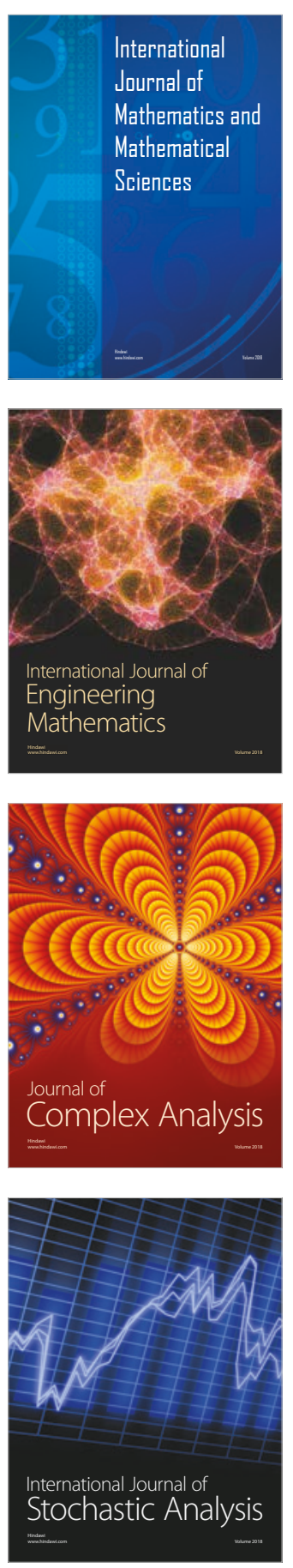
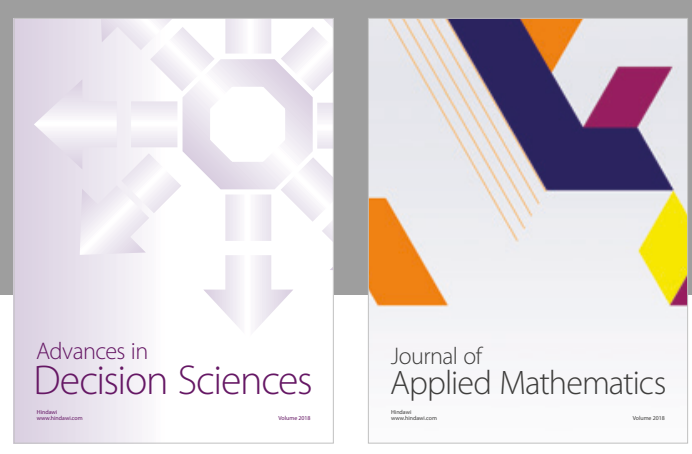

Journal of

Applied Mathematics
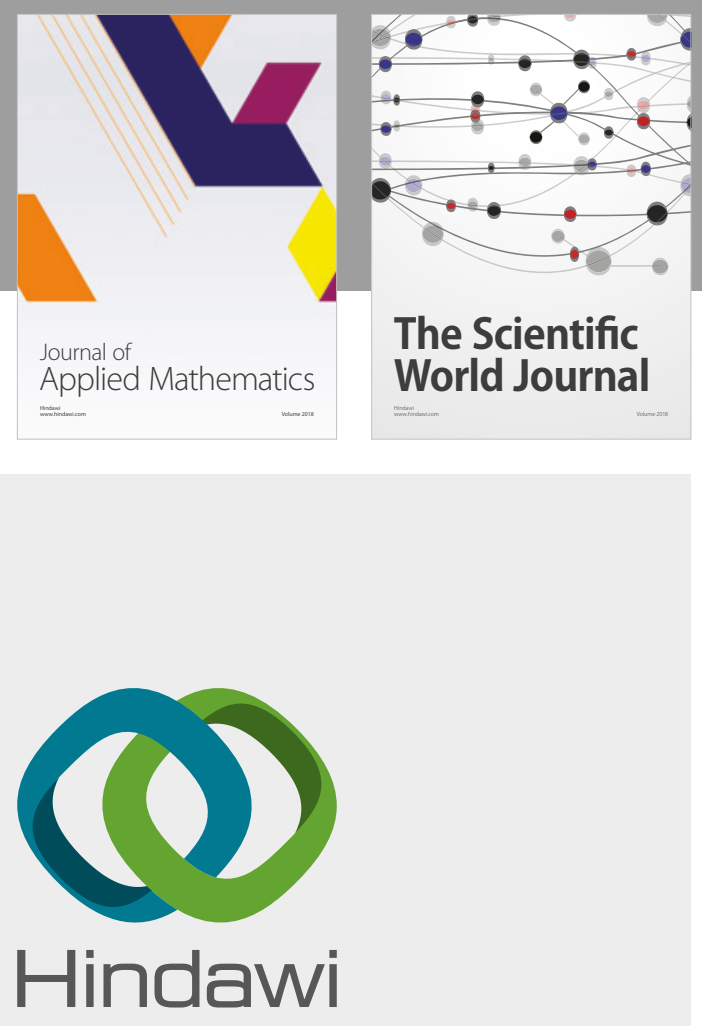

Submit your manuscripts at

www.hindawi.com

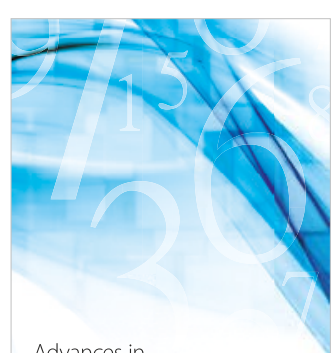

Advances in
Numerical Analysis
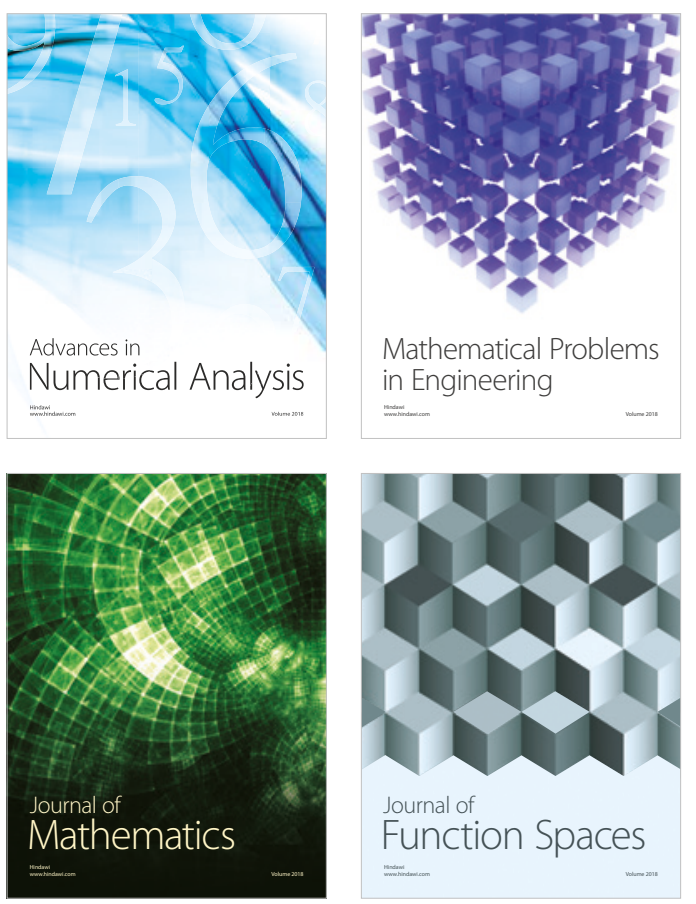

Mathematical Problems in Engineering

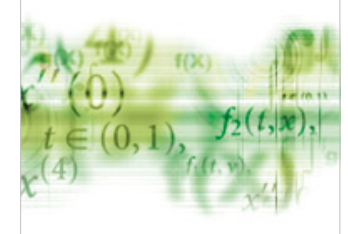

International Journal of

Differential Equations

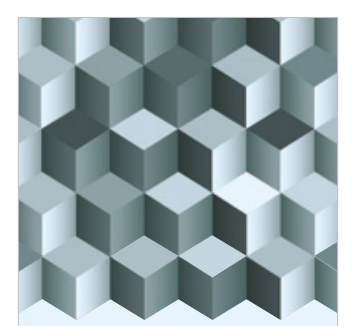

Journal of

Function Spaces
The Scientific

World Journal

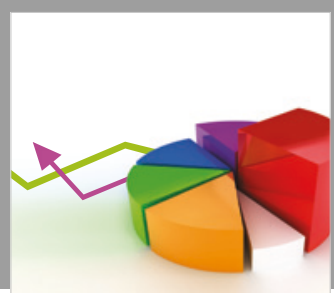

Journal of

Probability and Statistics
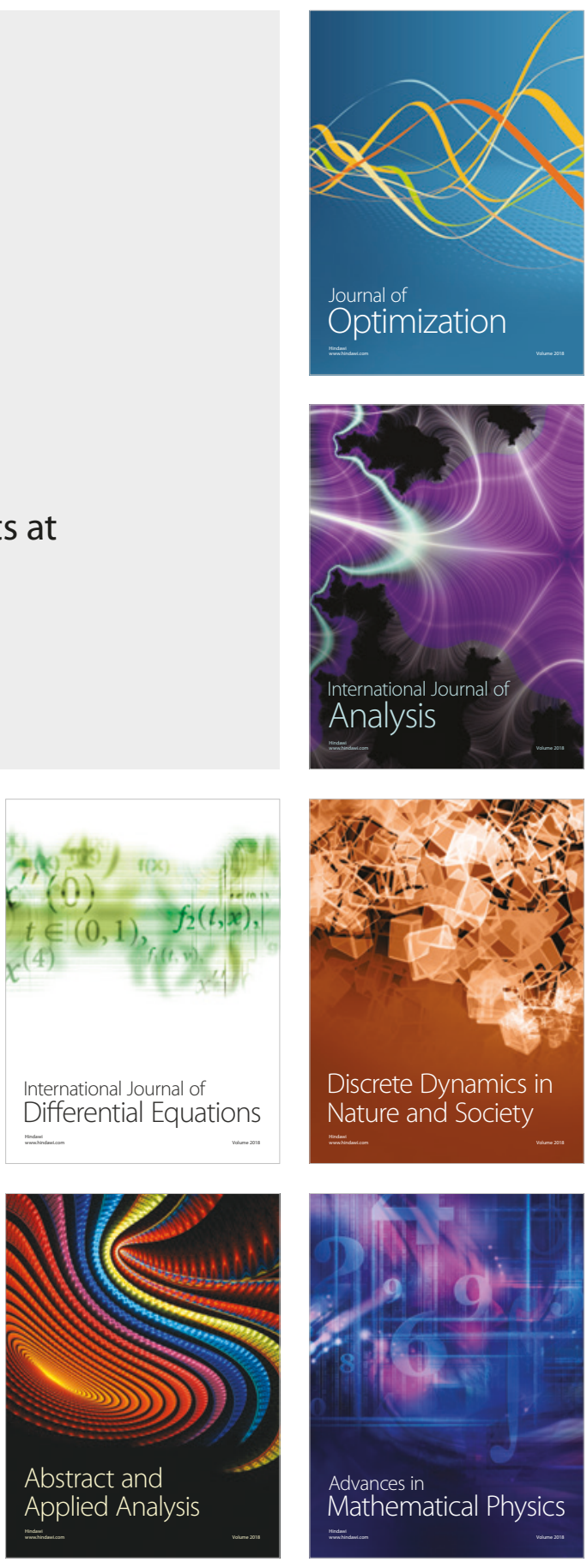